\title{
Capacity of Polysaccharide Accumulation by Whole Rumen Bacteria
}

\author{
By Rikiya TAKahashi and Hajime TAKahashi \\ Department of Agricultural Chemistry, Faculty of Agriculture, \\ Tohoku University, Sendai \\ Received July 5, 1967
}

\begin{abstract}
An optical density of a whole bacterial suspension, prepared from sheep rumen contents, increased very rapidly when the cells were incubated in a glucose-containing medium. This is largely due to the accumulation of intracellular polysaccharide(s) and appears to proceed without cell multiplication. The increase has an apparent relationship with feeding conditions of animals and reflects the availability of easily fermentable sugars for bacteria in the rumen. The data suggest that the ruminal fermentation proceeds under extremely low level of easily fermentable sugars.
\end{abstract}

\section{INTRODUCTION}

In the course of the study on the fractionation of ruminal bacteria on the basis of their differences in nutritional requirements, it was found that an optical density (O.D.) of a whole bacterial suspension, that was prepared from sheep rumen contents, increased very rapidly when the cells were incubated in a glucose-containing medium. The finding led the authors to examine the nature of this phenomenon and the bacterial capacity of this increase in relation to feeding conditions of animals.

The results indicate that this increase is due to the bacterial assimilation of glucose to form intracellular polysaccharide(s) and appears to reflect the conditions of ruminal fermentation which seems to proceed under extremely low level of easily fermentable sugars.

\section{MATERIALS AND METHODS}

Preparation of bacterial suspension from rumen contents. Two rumen-fistulated sheep were used in the present experiment. One sheep $(\mathrm{H})$ was maintained on $800 \mathrm{~g}$ of hay per day and the other $(\mathrm{HC})$ was fed $500 \mathrm{~g}$ of hay and $500 \mathrm{~g}$ of concentrate mixture once a day. Both animals were fed at 9 a.m.

Unless otherwise stated, rumen contents were taken from the sheep through the fistula before the feeding. The contents were filtered through a sheet of gauze, and were centrifuged at $27 \times \mathrm{g}$ for 5 minutes to remove protozoa and particulate materials. The resulting supernatant was recentrifuged at $10,000 \times \mathrm{g}$ for 30 minutes, and the bacterial fraction was obtained as the precipitate. Cells were washed once with a mineral solution and were suspended in an incubation medium at an O.D. of 0.2 to 0.4 .

Incubation of cell suspension. The incubation medium contained $0.4 \%$ of $\mathrm{Na}_{2} \mathrm{CO}_{3}, 0.05 \%$ of cysteine hydrochloride, $10 \%$ (V/V) of clarified rumen fluid which was prepared according to the method of Allison et al., ${ }^{1)}$ and, unless otherwise noted, $0.5 \%$ of glucose in the mineral solution. The mineral solution consisted of $0.045 \%$ of $\mathrm{K}_{2} \mathrm{HPO}_{4}, 0.045 \%$ of $\mathrm{KH}_{2} \mathrm{PO}_{4}$, $0.09 \%$ of $\mathrm{NaCl}, \quad 0.09 \%$ of $\left(\mathrm{NH}_{4}\right)_{2} \mathrm{SO}_{4} \quad 0.009 \%$ of $\mathrm{MgSO}_{4} \cdot 7 \mathrm{H}_{2} \mathrm{O}$, and $0.0090^{\circ}$ of $\mathrm{CaCl}_{2} \cdot 2 \mathrm{H}_{2} \mathrm{O}$. The incubation was done under $\mathrm{CO}_{2}$ atmosphere and at $38^{\circ} \mathrm{C}$.

Optical density values of the cultures were measured by a Hitachi FPW 4 colorimeter equipped with a 66 filter $(660 \mathrm{~m} \mu)$.

Determination of cell counts. Samples were taken from the incubation mixture at time intervals. Cells were harvested after centrifugation and were fixed with $1 \mathrm{ml}$ of $10 \%$ formaldehyde. Cells in the suspension

1) M.J. Allison, M. P. Bryant and R. N. Doetsch, J. Bacteriol., 83, 523 (1962). 
were counted microscopically with the aid of a PetroffHauser's chamber.

Assay of polysaccharide in bacterial cells. After the incubation, the culture $(10 \mathrm{ml})$ was immediately transferred into an ice bath and centrifuged at $10,000 \times \mathrm{g}$ for 30 minutes in the cold. The precipitate was washed once with the mineral solution, and was hydrolyzed with $12 \mathrm{ml}$ of $1 \mathrm{~N} \mathrm{HCl}$ for 2 hours at $100^{\circ} \mathrm{C}$. The reducing substance in the hydrolyzate was assayed by Somogyi's method, ${ }^{2}$ ) and was expressed as glucose. The polysaccharide of whole rumen bacteria was assayed similarly with samples which were taken directly from the rumen contents.

\section{RESULTS}

Change in O.D. of cell suspension during incubation with glucose

The cell suspension prepared from the HC animal was incubated in the glucose medium. As shown in Fig. 1, very rapid increase in O.D. was observed during the first 1-hour incubation.

The addition of inhibitors of glycolysis, such as sodium fluoride and monoiodoacetate, almost completely inhibited the increase. The ad-

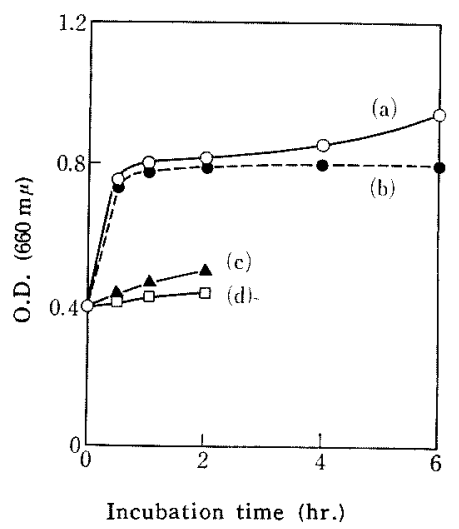

FIG. 1. Rapid Increase in Optical Density of Bacterial Cell Suspension Incubated in the Glucose Medium.

Cells were incubated in the glucose medium with following additions: (a) no addition, (b) penicillin $\mathrm{G} 1,000$ units $/ \mathrm{ml}$, (c) monoiodoacetate $(0.003 \mathrm{M})$, and (d) sodium fluoride $(0.003 \mathrm{M})$.

2) M. Somogyi, J. Biol. Chem., 195, 19 (1952). dition of penicillin $G$, however, had no or little effect on the first increase in O.D. but it inhibited the secondary increase that occurred after 4-hour incubation.

Change in cell number during the incubation

In order to know whether or not the increase in O.D. in the glucose medium was associated with cellular division, the measurement of total cell counts during the incubation was performed microscopically. As shown in Table I, it was found that the significant increase in cell number was not followed by the first increase in O.D., but the number of cells increased appreciably at the period of secondary increase in O.D. which occurred after 4-hour incubation.

Table I. Change in Bacterial Cell Counts DURING THE INCUBATION IN GLuCose MEdium

$\begin{array}{ccc}\begin{array}{c}\text { Incubation time } \\ (\mathrm{hr} .)\end{array} & \text { O.D. } & \begin{array}{c}\text { Bacterial cell } \\ \text { counts }\left(\times 10^{8} / \mathrm{ml}\right)\end{array} \\ 0 & 0.291 & 6.6 \\ 1 / 2 & 0.483 & 9.8 \\ 1 & 0.546 & 8.3 \\ 6 & 1.000 & 27.5\end{array}$

\section{Effect of cell concentrations on the increase in} O.D.

The bacterial cells from the $\mathrm{HC}$ animal were suspended in the glucose medium at

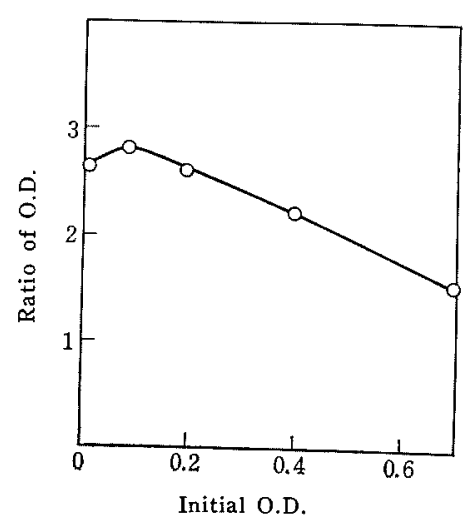

FIG. 2. Effect of Initial Concentration of Bacterial Cells on the Increase of Optical Density in the Glucose Medium. 
various cell concentrations. After 2-hour incubation, the ratio of O.D., that is, O.D. after the incubation/O.D. before the incubation, was plotted versus initial cell concentrations. As shown in Fig. 2, the differences in ratios were not great within the range from 0.2 to 0.4 . Thus the data with different initial cell concentrations could roughly be compared each other by the ratios.

Effect of nitrogen source on the increase in 0.D. The cell suspension from the $\mathrm{HC}$ animal (initial O.D. $=0.33$ ) was incubated in the medium from which nitrogen sources were omitted. As shown in Table II, the ratios obtained by 2-hour incubation were approximately the same either in the presence or absence of nitrogen source, provided glucose was included in the media. Therefore, it is apparent that nitrogen sources are not required for the increment.

TABLE II. EFFECT OF NITROGEN SOURCES ON THE OPTICAL DENSITY INCREASE

Incubation media

Complete

$-\left(\mathrm{NH}_{4}\right)_{2} \mathrm{SO}_{4}$

$-\left(\mathrm{NH}_{4}\right)_{2} \mathrm{SO}_{4},-$ rumen fluid

- Glucose

Relationship between glucose concentration and the increase in $0 . D$.

The cell suspension from the $\mathrm{HC}$ animal (initial O.D. $=0.4$ ) was incubated in the media

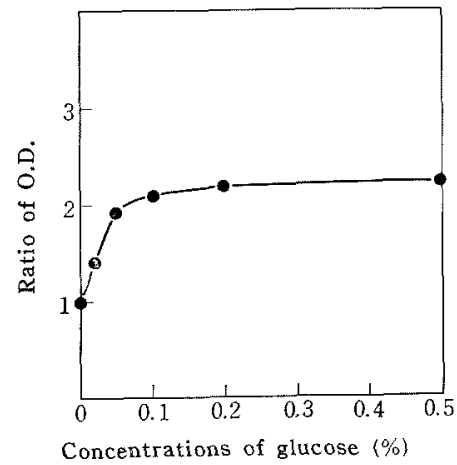

FIG. 3. Effect of Glucose Concentrations upon the Optical Density Increase. with various amounts of glucose which ranged from $0.01 \%$ to $0.5 \%$. After 2-hour incubation, O.D. of the cultures were recorded. In Fig. 3, the ratio is plotted versus initial concentration of glucose. As shown, the increment in O.D. paralleled with the increase of glucose concentration up to $0.1 \%$. No more increase was noticed at higher concentration of glucose. Evidently, the bacterial activity, as judged by the increment in O.D., was saturated at glucose concentrations over $0.1 \%$.

Effectiveness of various carbohydrates as substrate

The effectiveness of various carbohydrates as substrate for the increase in O.D. was tested with the media which contained $0.5 \%$ of the specified carbohydrate instead of glucose. The bacterial suspension from the $\mathrm{HC}$ animal was incubated in each medium for 2-hours. The effectiveness of each substrate is compared by the ratio of O.D. and is summarized in Table III. It was found that not only glucose, but fructose and sucrose were also effective among carbohydrates tested.

TABLE III. INCREASE OF OPTICAL DENSITY WITH VARIOUS SUBSTRATES

\begin{tabular}{lc}
\multicolumn{1}{c}{ Substrates added } & Ratio of O.D. \\
None & 1.00 \\
Arabinose & 1.18 \\
Ribose & 0.95 \\
Xylose & 1.00 \\
Fructose & 1.79 \\
Galactose & 1.00 \\
Glucose & 1.93 \\
Mannose & 1.00 \\
Cellobiose & 1.08 \\
Lactose & 1.15 \\
Maltose & 1.26 \\
Sucrose & 1.71 \\
Carboxymethyl cellulose & 1.00 \\
Starch & 1.06
\end{tabular}

Consumption of glucose and accumulation of polysaccharide in bacterial cells

In Fig. 4 the relationship between the increase in O.D. and the increment in dry weight of cell mass is presented. The result 


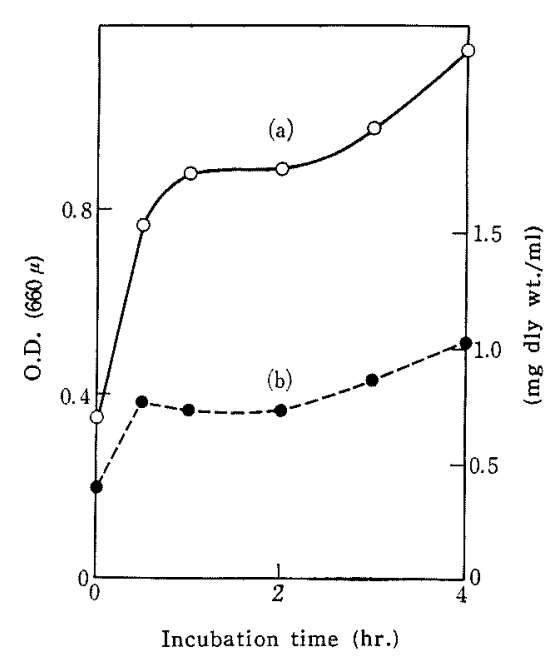

FIG. 4. Increase in Dry Weight of Cells during the Incubation in the Glucose Medium.

Optical density increase was plotted versus incubation time (a). A portion of the culture was centrifuged in the cold. The cells were washed with water and dried at $92^{\circ} \mathrm{C}$. The data of dry weight measurements were also plotted versus incubation time (b).

indicates that the increase in O.D. during the first 1-hour incubation is due to the bacterial assimilation of glucose, since the increase in O.D. is associated with the gain in dry weight. The consumption of glucose in the medium and the accumulation of polysaccharide in bacterial cells are shown in Fig. 5. During the incubation of 2 hours, the cells (initial dry weight $=0.4 \mathrm{mg} / \mathrm{ml}$ ) consumed $0.65 \mathrm{mg}$ of glucose $/ \mathrm{ml}$. Hydrolysis of the incubated cells $(0.74 \mathrm{mg}$ dry weight $/ \mathrm{ml})$ resulted in the formation of $0.24 \mathrm{mg} / \mathrm{ml}$ of reducing material as glucose. It is apparent, therefore, that approximately $70 \%$ of the increment in cell mass is due to the accumulation of polysaccharide within cells. About $37 \%$ of glucose, that is consumed during the incubation, is recovered as polysaccharide.

Capacity of bacterial assimilation of glucose in relation to feeding conditions

Bacterial fractions from rumen contents of the $\mathrm{H}$ and $\mathrm{HC}$ animals were prepared just

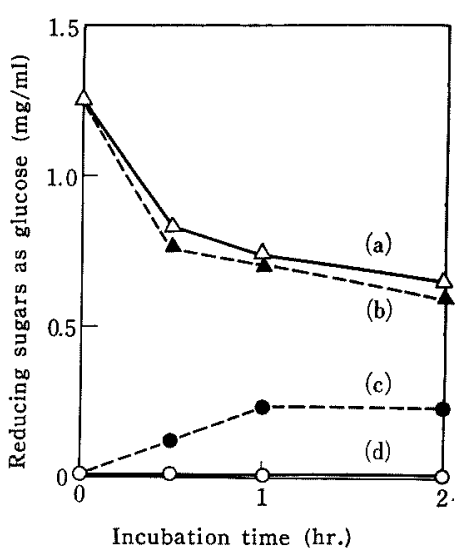

FIG. 5. Consumption of Glucose and Accumulation of Polysaccharide by Bacterial Cells during Incubation in the Glucose Medium.

A portion of the culture was withdrawn as time intervals. Cells and the medium were separated by centrifugation. Reducing material in both fractions was assayed with or without acid hydrolysis pretreatment.

Following symbols represent the amount of reducing material as glucose in hydrolyzed medium (a), the medium, not hydrolyzed (b), hydrolyzed cells (c), and cells, not hydrolyzed (d).

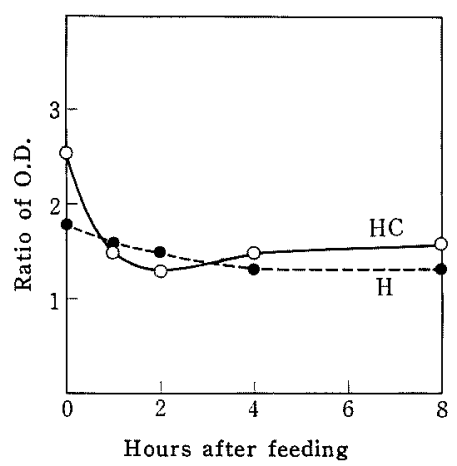

FIG. 6. Capacity of Bacterial Assimilation as Related to the Feeding.

The feeding was started at zero time. Bacterial suspensions were prepared from the rumen contents of the $\mathrm{H}$ and $\mathrm{HC}$ animals taken just before the feeding $(0)$ and at time intervals as indicated. They were incubated in the glucose medium for 2 hours. The capacity of the increment in optical density of each suspension was expressed by the ratio of optical densities. 
before the feeding and at 2-hour intervals after the feeding. Each suspension (initial O.D.=approximately 0.3 ) was incubated in the glucose medium for 2 hours. In Fig. 6 the ratio of O.D. is plotted versus time after the feeding. As shown, the ratio has an apparent relationship with feeding conditions, being highest before the feeding and decreased thereafter in both cases. After 2 hours from the feeding, only a little increase in O.D. is observed with the bacterial fraction from the $\mathrm{HC}$ animal. The result suggests that the ruminal bacteria at this time are almost saturated with easily fermentable sugars. The gradual increase of the ratio after 4 hours might be explained by the decreased level of easily fermentable carbohydrates in the rumen contents. In contrast to the bacterial fraction from the $\mathrm{HC}$ animal, response to glucose of the ruminal bacteria from the $\mathrm{H}$ animal was less active. The minimum ratio was slowly reached at 4- to 8-hour incubation, indicating the meager supply of sugars in the rumen of the $\mathrm{H}$ animal.

Accumulation of polysaccharide in vivo In view of above results, it is supposed that

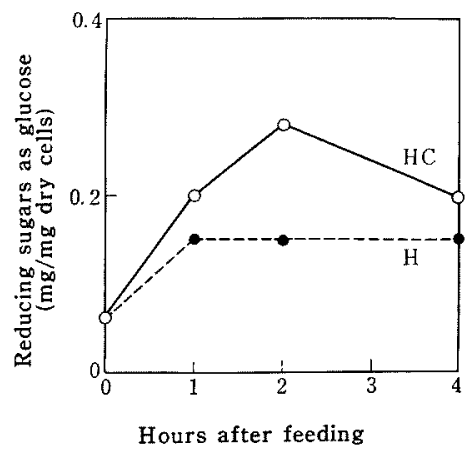

FIG. 7. Accumulation of Polysaccharide in Ruminal Bacteria in vivo.

The feeding was started at zero time. Bacterial fraction was taken from rumen contents of the $\mathrm{H}$ and $\mathrm{HC}$ animals just before feeding $(0)$ and at time intervals as indicated. The reducing material in each bacterial fraction was assayed after the acid hydrolysis. polysaccharide is also accumulated in ruminal bacteria after the feeding of the animals. To test this possibility, bacterial fractions were prepared from the $\mathrm{H}$ and $\mathrm{HC}$ animals before and after the feeding. They were acidhydrolyzed and polysaccharide in cells was estimated as before. Fig. 7 shows that the amount of polysaccharide in the $\mathrm{HC}$-cells was the highest at 2 hours after the feeding and decreased gradually after this period. The accumulation of polysaccharide in the H-cells increased slowly for 1 hour and maintained its level until 4 hours after the feeding. These observations are in agreement with the in vitro experiment.

\section{DISCUSSION}

The first and rapid increase of O.D. of ruminal bacteria that occurred in the glucose medium seems to proceed without bacterial multiplication. Since, contrary to the secondary increase, penicillin $G$ does not inhibit the first increase, the increase also occurred in the nitrogen-free media and no significant increase in cell counts was observed. The increase in O.D. is mostly due to the accumulation of polysaccharide within cells. The assimilation of glucose by whole ruminal bacteria is extremely efficient, since approximately $37 \%$ of glucose that is metabolized is converted to intracellular polysaccharide. Accumulation of polysaccharide by whole rumen bacteria in glucose-containing media has been observed by a number of workers mostly by iodine staining, but no such increase in O.D. has been described thus far..$^{3 \sim 51}$

The finding that starch and carboxymethyl cellulose are poor substrates for this assimilation indicates relatively low activity of amylase and cellulase in bacterial cells. Cellobiose, which is known as a preferable carbon source

3) A. M. Smith and F. Baker, Biochem. J., 38, 496 (1944).

4) R. J. Gibbons, R. N. Doestsch and J. C. Shaw, Dairy Sci., 38, 1147 (1955)

5) P.J. Heald, Brit. J. Nutr., 5, 84 (1951). 
to glucose for certain species of ruminal bacteria, ${ }^{61}$ also failed to support the assimilation.

It was an unexpected finding that the O.D. of bacterial suspension, that was taken from rumen contents before the feeding, increased approximately twofold or more in the glucose medium. It might be said that this is a general phenomenon in sheep rumen bacteria, because such large increase can not be attributed to the activity of a small fraction of ruminal bacteria.

The capacity of bacterial assimilation of glucose as determined by the ratio of O.D. has an apparent relationship with the feeding conditions. As shown with the $\mathrm{HC}$ animal, only a little increase in O.D. was observed with the bacterial suspension obtained after 2 hours from the feeding. The bacteria seem to be saturated with easily fermentable sugars at this period. The saturation, however, was observed only at this period in the HC cells. The results indicate that the ruminal fermentation proceeds under extremely low level of

6) M. P. Bryant, Bacteriol. Rev., 23, 125 (1959). easily fermentable sugars. The analysis of intracellular polysaccharide of cells obtained directly from the rumen contents also supported the above thesis. Thus the capacity of O.D. increase of whole rumen bacteria in the glucose medium may be taken as an index which represents the availability of easity fermentable sugars for the bacteria in the rumen.

The capacity of polysaccharide accumulation of ruminal bacteria appears to contribute to some extent for the maintenance of the low level of easily fermentable sugars which is supposed to be an essential condition for the production of volatile fatty acids in the rumen. It is known that the excess feeding of carbohydrates to ruminants causes death of animals due to the accumulation of lactic acid, an unfavorable fermentation product, in the rumen. $^{7}$ In this connection, it is of some interest to note that the capacity of polysaccharide accumulation is higher in the $\mathrm{HC}$ population than that in the $\mathrm{H}$ population.

7) E.F. Annison and D. Lewis, "Metabolism in the Rumen", Methuen and Co., London, 1959, p. 167. 